\title{
UNUSUAL RESPONSES TO DRUGS IN SOME HEREDITARY CONDITIONS*
}

\author{
W. KALOW, M.D. $\dagger$
}

AN UNUSUAL RESPONSE to a drug may have disastrous consequences, or may be a mere nuisance, but-if studied systematically-unusual responses offer new insight into the normal mode of action of drugs. One may facilitate such a systematic study by dividing unusual drug responses into two large categories: those arising from external influences, and those caused by hereditary conditions. At the present state of knowledge, it is not always possible to divide drug reactions in this manner but clear-cut examples of such external factors are death due to atropine in hot weather ${ }^{1}$ when interference with perspiration may cause heat stroke ${ }^{2}$ or, as has been recently claimed, an increased risk of general anaesthesia after exposure to iradiation. ${ }^{3}$ The purpose of the present paper is to give examples of drug reactions which have in common that they obey the rules of heredity; application of these rules will gradually reduce some elements of surprise in the use of drugs and thereby increase their safety.

The following discussion will deal mostly with drugs of some concern to anaesthetists and it should be kept in mind that genetically determined deviations from a usual drug response occur in organisms of all kinds. Resistance of bacteria to penicillin develops if there are a few individual organisms in a colony which are resistant to this antibiotic and which get a chance to spread and multiply if the colony is exposed to penicillin. ${ }^{4}$ In a similar way, the resistance of insects to insecticides is evidence for genetically determined variations in the response to these agents. ${ }^{5}$ Some strains of mice are more susceptible to the toxic action of pentobarbital than other strains, and these differences between strains are heritable. ${ }^{6}$ Some rabbits have, anc others lack, the enzyme atropine esterase $;^{7}$ those which have the enzyme show fleeting effects of atropine. ${ }^{8}$ Of the heritable influences on drug response in man, I want to mention only two which affect anaesthesia indirectly. First, some types of haemolytic reaction from coal tar analgesics, sulphonamides, or antimalarials like primaquin are due to an inherited enzymatic defect in red cells. ${ }^{9}$ This defect occurs in Negroes more often than in Caucasians. Second, the antituberculous drug isoniazid is metabolized by some people faster than by others; ${ }^{10}$ those who do not readily metabolize the drug are prone to develop a secondary vitamin $\mathrm{B}_{6}$ (pyridoxine) deficiency, ${ }^{11}$ a deficiency which may find expression in various neurological disorders. The hereditary determination of isoniazid metabolism has been established recently. ${ }^{12}$

*Department of Pharmacology, University of Toronto.

†Presented atghe Second World Congress of Anaesthesiologists, Sept. 4-10, 1960, Toronto, Ontario.

Can. Anaes. Soc. J., vol. 8, no. 1, January, 1961 
We will now turn to some drugs used in anaesthesia. The outcome may be very serious if barbiturates are administered to patients, suffering from porphyria. ${ }^{13}, 14$ There are several forms of porphyria; ${ }^{15}$ most important is the acute intermittent type of this disease. ${ }^{14}$ We still do not know its biochemical cause but research of the past 15 years has eliminated the misconception that porphyrins are poisonous breakdown products of heme. The work of Rimington, Waldenström, Shemin, Gibson, Granick, and many others has conclusively shown that porphyrins are precursors of heme. ${ }^{16.17}$ It appears likely that the metabolic error in porphyria involves some of the simple biochemical building stones, namely acetic acid and glycine. Proper utilization of these agents for heme synthesis requires oxidative phosphorylation which can be blocked by barbiturates. ${ }^{18} \mathrm{~A}$ derangement of this or another similarly fundamental biochemical event is probably responsible for the initiation of a porphyric attack. Metabolic products which appear in human urine during a porphyric attack are often precursors of porphyrins, rather than porphyrins themselves. The porphyrins have a red colour and can, therefore, be seen in urine, but the rre-

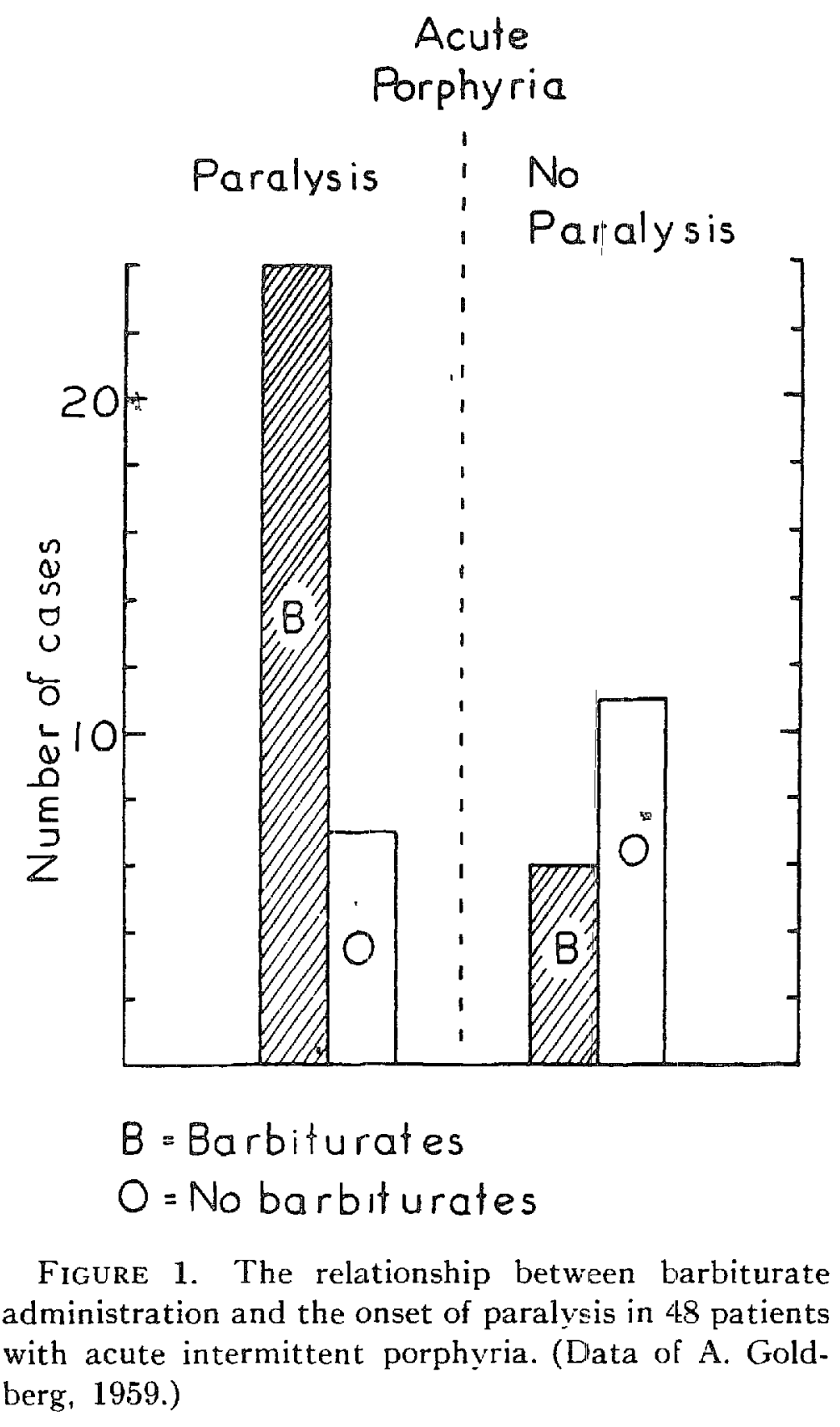


cursors are colourless. Fortunately, porphobilinogen can be demonstrated with a very simple laboratory test. ${ }^{19}$ Anatomical lesions of porphyria may consist in patchy demyelination which mily be related to autonomic symptoms, to paralysis of motor nerves, and to mental disturbances. ${ }^{14}$ A fairly consistent sign is a rapid heart rate, often combined with hypertension. The presenting symptom is frequently abdominal pain of such severity that surgery seems indicated. Under these circumstances thiopental may change the character of the attack and produce paralysis, ${ }^{14}, 20$ which may be fatal by interference with respiration or, if not fatal, may cause a patient to be bedridden for periods of weeks and perhaps months. Not all persons with the hereditary defect develop clinical symptoms. Thus the disease may not be evident in every carrier of the gene; yet one gene is sufficient to produce the disease, that is, inheritance is dominant. ${ }^{21}$

Another hereditary condition which affects the practice of anacsthesia is the occurrence of atypical pseudocholinesterase in the serum of some persons. ${ }^{22}$ This unusual enzyme does not seem to cause any disease but it fails to hydrolyse succinycholine in clinical concentration:s, ${ }^{23}$ so that the relationship between relaxant dose and duration of action is quite different in persons with atypical esterase and in those with the usual type of enzyme. In a sense, it is wrong to speak of a prolonged apnoea after succimylcholine, if a person $\mid$ has atypical esterase; the long duration of action is a predictable, reproducible, and thus regular occurrence. With proper artificial respiration the patient also seems to

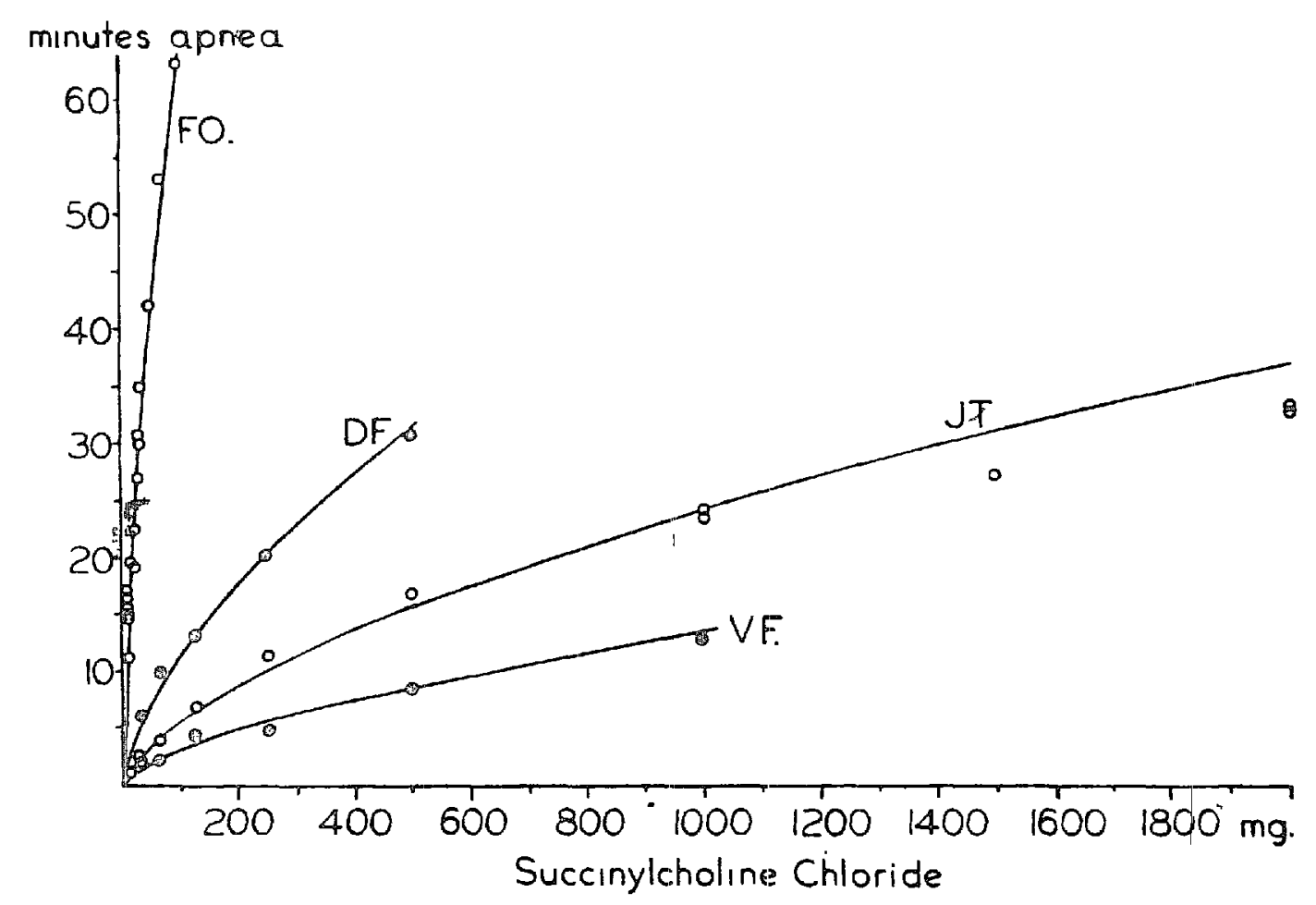

FIgURE 2. Relation between dose of succinylcholine chloride and duration of apnoea in 4 representative patients. Varjous doses were administered at intervals of days or weeks for electroshock treatment.

Patient V.F. represents a case with a high level of usual type of esterase; Patient J.T., low level of usual type of esterase; Patient D.F., mixture of normal and atypical esterase with preponderance of the latter; Patient F.O. atypical esterase. (Data of Kalow and Gunn, 1957.) 


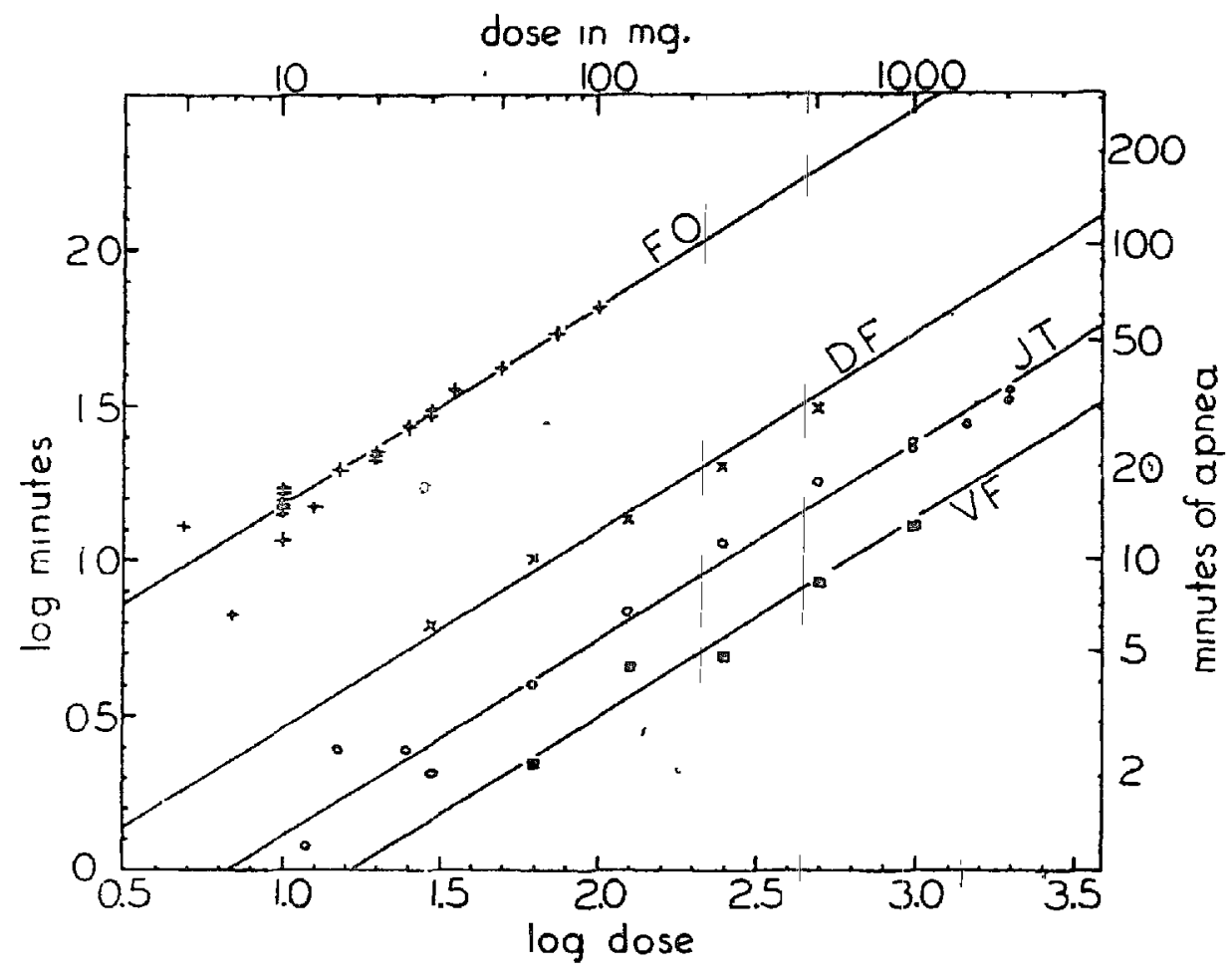

Figure 3. Same data as in Figure 2 on a logarithmic plot. (Figure by Kalow and Gunn (1957) reproduced with permission of the J. Pharmacol. \& Exper. Therap.)

be quite safe after succinylcholine even if one has to wait for a few hours until the drug effect is over. One cannot get a short action of succinylcholine in these patients since they need $10 \mathrm{mg}$. of succinylcholine for relaxation and since even this small dose can be expected to act for 10 minutes. It is important to appreciate that equipment for arkificial respiration ought to be immediately avail. able, even if one administers dnly a test dose of the drug. About 1:2,000 or 3,000 patients have the atypical esterase $;^{24}$ much more frequent are persons who have a mixture of normal and atypical esterase in their serum. They are the heterozygotes and constitute nearly 4 per cent of the population. There is clinically little trouble with these heterozygotes. Their plasma hydrolyses succinylcholine at about half the normal rate. In a person with the normal type of cholinesterase, reduction of esterase activity to one-half normal in the presence of cancer or liver disease ${ }^{25}$ is likely to be accompanied by some prolonged effect of succinylcholine unless the dose is reduced. One must consider the possibility that the liver damage as such may influence the duration of drug action by some means which is independent of cholinesterase. I should like to mention that any attempt to detect heterozygosity by simple measurements of reaction rate ${ }^{26}$ does permit the recognition of not more than twothirds of the heterozygotes. ${ }^{27}$

In hypokalemic hereditary periodic paralysis, attacks have been induced by glucose, insulin, ${ }^{28}$ or chlorothiazide. ${ }^{29}$ There is, however, a very rare hyperkalemic form of this disease in which anaesthesia appears to precipitate severe paralysis. ${ }^{30}$ For example, thiopental given for a dental extraction left a patient unable to move for several hours after awakening. Similar attacks have occurred 
in two women after childbirth under anaesthesia; one of the women delivered another child with spinal anaesthesia without sustaining-an attack.

An inherited anatomical feature ${ }^{31}$ which may spell trouble for the anaesthetist is a narrow angle between cornea and iris, that is, a shallow anterishamber of the eye. This narrow angle is a prerequisite ${ }^{32}$ for the primary acuie glaucoma, while the simple chronic glaucoma frequently occurs in eyes with a wide angle. A sharp distinction between the glaucomata is necessary since the action of some drugs on intraocular pressure is different in these conditions. ${ }^{33}$ During pupillary dilatation, the iris may crowd the drainage canals of the aqueous humour if there is a narrow angle, but not if the angle is wide. Hence the

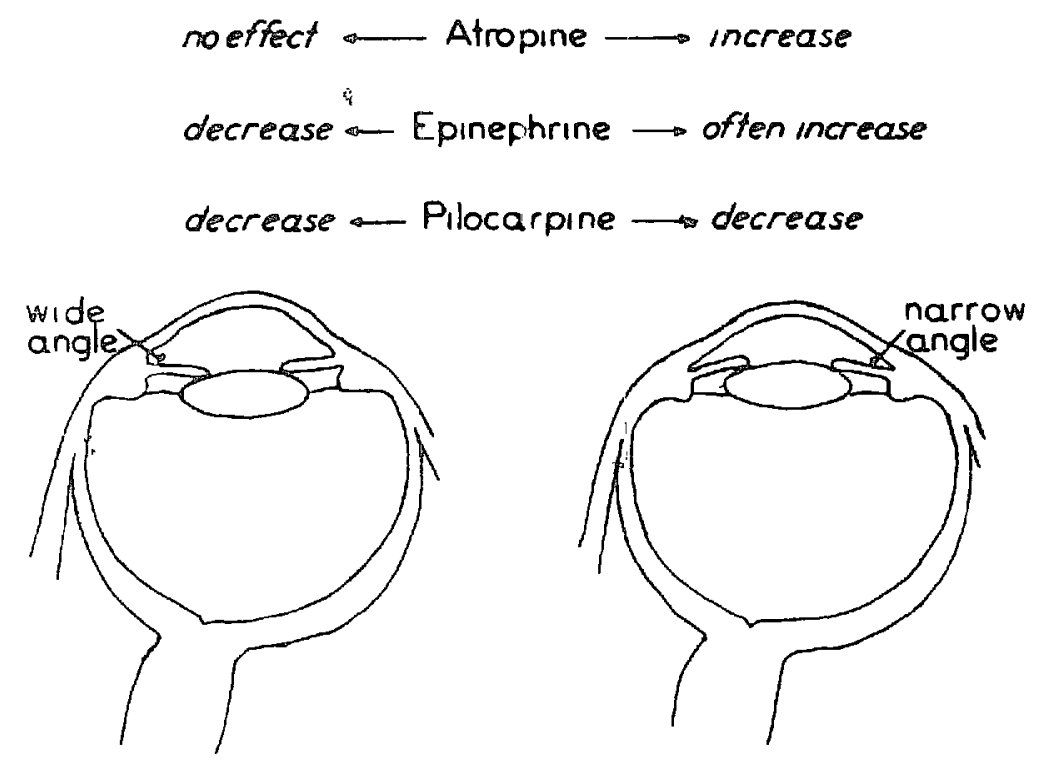

Figure 4. Differential effects of drugs on intraocular pressure in narrow-angle and in wide-angle glaucoma. See text for further explanation.

mydriatic action of atropine blocks the drainage with a consequent rise of intraocular pressure in acute glaucoma, but it has little effect on the pressure in simple "glaucoma and on a normal eye. Strangely enough, this distinction does not have to be made if the opposite pharmacological effect is sought, since cholinergic stimulation, as, for instance, exerted by pilocarpine, reduces intraocular pressure in any type of glaucoma. On the other hand, adrenergic agents reduce intraocular pressure in simple glaucoma but enhance the pressure in acute glaucoma. This double action has been observed with epinephrine, phenylephrine, ${ }^{34}$ ephedrine, and cocaine. ${ }^{33}$

Since epinephrine is frequently liberated during general anaesthesia, ${ }^{35}$ this double action may well explain why some observers find that general anaesthetics lower intraocular pressure, ${ }^{36}$ and yet glaucomatous attacks have been initiated by general anaesthesia and surgery ${ }^{37}$ In these cases, the attack may be the combined result of preoperative atropine enhancing the pupillary dilatation of deep andesthesia, and of epinephrine liberation due to anxiet $y^{38}$ and the action of, tor example, ether. Succinylcholine is able to raise the intra ocular pressure but this is a relatively minor effect of short duration; the 
pressure rises more as a result of intubation than of the drug. ${ }^{39}$ If one suspects a narrow-angle glaucoma, a prophylactic drop of 2 per cent pilocarpine preoperatively is indicated. ${ }^{37}$

In short, the relatively frequent, slowly progressing, simple glaucoma of old age is nothing which the anaesthetist has to fear, but this is no reason to neglect the dangers of the relatively rare, acute, narrow-angle glaucoma. The most likely candidates for this latter glaucoma are elderly women. The prodromal stages are characterized by a combination of sporadic headache with the appearance of halos resulting from corneal oedema. A single observation of a normal intraocular pressure does not exclude the presence of the disease. The mode of inheritance seems to be variable but a question for acute glaucoma among relatives of the patient may be worth while. ${ }^{40}$

The colour of the iris is genetically determined. The different content of pigment reflects a difference in biochemical make-up. It is known that irises of

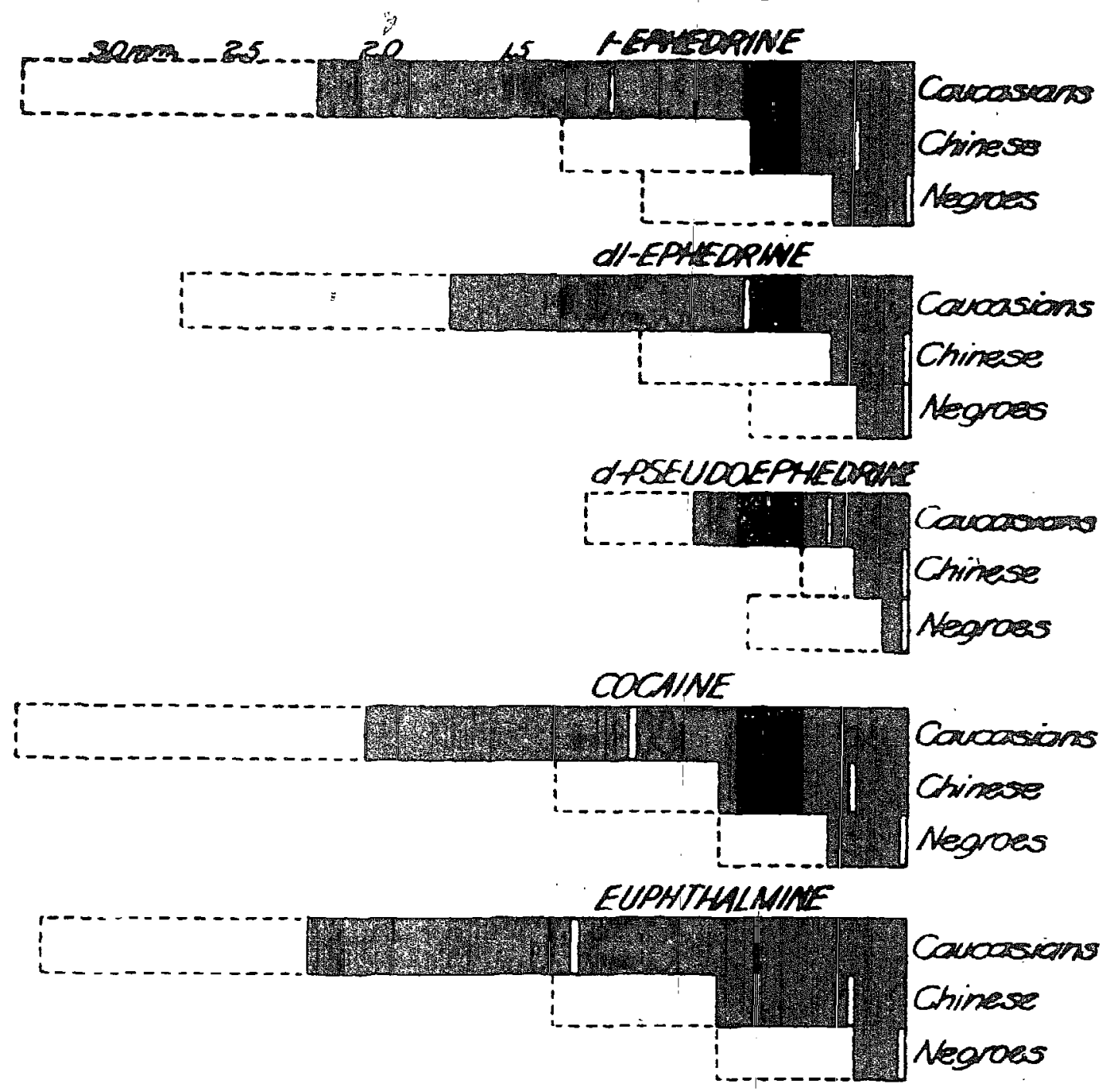

Figure 5. Comparison of the mydriatic action of 1-ephedrine, d1-ephedrine, d-pseudoephedrine, cocaine, and euphthalamine in Caucasians, Chinese, and Negroes. Each scale expressed in millimeters represents the results of 10 subjects. The solid scaledenotes the average increase of the transverse diameter of the pupil. The solid scale plus that enclosed in the broken lines indicates the maximum value in the series, and that portion of the solid scale on the right side of the white vertical line the minimal value in the same series. (Reproduced by permission of $K$. K. Chen and the J. Pharmacal. \& Exper. Therap.) 
different colour contain different activities of dopa oxidase. ${ }^{41}$ While not all the biochemical relationships are understood, there is no doubt that eyes of different colour react with different intensity to mydriatic agents. This has been shown for rabbit eyes ${ }^{41}$ but It holds for human eyes as well. ${ }^{42,}{ }^{43} \mathrm{~K}$. K. Chen, who with Carl F. Schmidt introduced the Chinese drug ephedrine into Western medicine, found that sympathomimetic drugs including cocaine had a strong mydriatic effect on European eyes, a moderate effect on Chinese eyes, and practically no effect on Negro eyes. ${ }^{44}$ It is very likely that this reflects a different metabolism of aromatic amines, including epinephrine. In this connection it is interesting to note the observation of an Australian dentist, Dr. Sutton, who claims that persons with dark eyes are more susceptible to pain than persons with light eyes. ${ }^{45}$ The contents of his article, plus comments, were published as an Editorial in the British Medical Journal, ${ }^{46}$ which initiated quite a flow of letters. The possibility of an indirect though real connection between eye colour and such a complex function as pain, should be investigated on a biochemical, not emotional, basis. There are several examples in biochemical genetics of a relation between pigmentation and other factors. For instance, the atropine esterase in rabbits is genetically linked with fur colour. ${ }^{7}$ Genes which affect the colour of mouse hair are known at at least twenty-four different loci; at eight of these loci are genes with highly specific effects on other characters. ${ }^{47}$ In human beings, the metabolic error of phenylketonuria causes mental deficiency accompanied by light eyes and blond hair. I wonder whether there is any truth in the old tale that red-haired patients tend to bleed excessively during surgery?

There have been reports from the United States, ${ }^{48,}{ }^{49}$ Jamaica, ${ }^{50}$ Africa, ${ }^{51}$ and the Fiji Islands, ${ }^{52}$ stating that the operative mortality of persons with dark skin pigmentation is greater than those with light skin. Circulatory collapse seems to play a major role in this morality. Efforts have been made, particularly in Jamaica, to sort out the various responsible factors. Persons of African descent showed regularly a high rise of blood sugar during an operation which indicates an excessive response of the adrenal medulla; ${ }^{53}$. on the othet hand, the adrenal cortex was found to be anatomically small ${ }^{54,55}$ and the urinary excretion rate of 17 ketogenic steroids to be low. ${ }^{56}$ One may speculate that this adrenal imbalance in conjunction with the low blood volume characteristic of undernutrition is the cause of the fatal collapse. In any case, there are probably both genetic and environmental factors in operation, the relative. importance of which is still to be elucidated.

The cases mentioned indicate the diversity which hereditary influences may have on the response to drugs. Some of the conditions described are rather rare; one may raise the question, why bother with such rarities-yet the study of exceptions is the best means of recognizing ordinary rules.

Many environmental, non-hereditary, and pathological coriditions such as undernutrition, obesity, bleeding, or cardiovascular dysfunction are either obvious or easily revealed by physical examination. The biochemical individuality which affects the response to drugs often tends to be hidden. Yet in view of the serious consequences which may be blindness, paralysis, or even 
death, a preoperative question as to unusual drug responses in the family might be worthwhile. If one suspects an hereditary nature of a rare, unusual response to a drug, it is important to find out whether there is a blood relationship between the parents.

One always has to keep in mind that the Gauss-curve, that is the normal, bell-shaped distribution curve of drug response, is oiten not applicable when one is dealing with unusual drug responses. This has numerous consequences; for instance, the concepts of gene frequency, of geneic polymorphism, and of heterozygous carriers, are likely to assume some new importance. Anaesthetists who are trained to record drug responses in 1 position to detect a wide variety of hereditary fa effect of drugs.

\section{REFERENCES}

1. JAHNkE, W. Atropinvergiftungen im heissen Klima. Archiv fur Toxicologie 16: 243 (1957).

2. Ford, W. L. Heat Stroke with Mepazine Treatment. Am. J. Psychiat. 116: 357 (1959).

3. ZAUDer, H. L., \& Orkin, L. Ionizing Radiation and Anesthetic Risks. Med. Klin. (Berl.) 55: $239(1960)$.

4. Pollock, M. R. Drug Resistance and Mechanisms for its Development. Brit. M. Bull. $16: 16(1960)$.

5. Brown, A. W. A. Insecticide Resistance in Arthropods. W.H.O. (Geneva). Monograph 38 (1958).

6. MCLaren, A., \& Michie, D. Variability of Response in Experimental Animals: A Comparison of Reactions of Inbred $F_{1}$ Hybrid and Random Bred Mice to a Narcotic Drug. J. Genet. 54: 440 (1956).

7. Säwin, P. B., \& Glick, D. Hydrolysis of Atropine by Esterase Present in Rabbit Serum Proc. Nat. Acad. Sc. 29: 55 (1943).

8. Werner, G., \& WURKer, R. Untersuchungen zur Mydriasis bei Kaninchen durch (-). Hyoscyamin. Naturwiss. 22: 627 (1959).

9. Beutler, E. The Hemolytic Effect of Primaquine and Related Compounds: A Review Blood 24: 103 (1959).

10. Hughes, H. B.; Biehl, J. P.; Jones, A. P.; \& Schmidt, L. H. Metabolism of Isoniazid in Man as Related to the Occurrence of Peripheral Neuritis. Am. Rev. Tuberc. 70: 266 (1954).

11. McСormick, D. B., \& Snell, E. E. Pyridoxyl Kinase of Human Brain and its Inhibition by Hydrazine Derivatives. Proc. Nat. Acad. Sc. 45: 1371 (1959).

12. Price Evans, D. A.; Mantey, K. A., \& McKusick, V. A., Genetic Control of Isoniazid Metabolism in Man. Brit. Med. J. ii: 485 (1960).

13. Dean, G. Porphyria. Brit. Med. J. ii: 1291 (1953).

14. Goldberg, A. Acute Intermittent Porphyria. A Study of 50 Cases. Quart. J. Med. 28: 183 (1959).

15. Waldenström, J. The Porphyrias as Inborn Errors of Metabolism. Amer. J. Med. 21: 758 (1959).

16. Granick, S., \& Manzerall, D. Enzymes of Porphyrin Synthesis in Red Blood Cells. Ann. N.Y. Acad. Sc. 75: 115 (1958)

17. London, 1. M. Metabolism of the Mammalian Erythrocyte. Bull. N.Y. Acad. Med. $86:$ $79(1960)$.

18. Hunter, F. E., \& Lowry, O. H. The Effects of Drugs on Enzyme Systems. Pharm. Rev. $8: 135(1956)$.

19. Watson, C. J., \& Schwartz, S. A Simple Test for Urinary Porphobilinogen. Proc. Soc. Exp. Biol. Med. 67: 393 (1941).

20. Waldenstróm, J. Porphyrie und Arzneimittel. In Nebenwirkungen von Arzneimitteln auf Blut und Knochenmark. Stuttgart: F. K. Schattauer-Verlag (1957) 
21. Dean, G., \& Barnes, H. D. Porphyria in Sweden and South Africa. S. Afr. Med. J. 88: 246 (1959).

22. Kalow, W. Cholinesterase Types. Ciba Found. Symp. Biochemistry of Human Genetics, p. 39. London (1959).

23. Kalow, W. "The Distribution, Destruction and Elimination of Muscle Relaxants. Anesthesiology 20: 505 (1959).

24. Kalow, W., \& Gunn, D. R. Some Statistical Data on Atypical Chloinesterase of Human Serum. Ann. Human Genetics 28: 239 (1959).

25. Wetstone, H. J.; LaMotta, R. V.; Bellucci, A.; Tennant, R.; \& White, B. V. Studies of Cholinesterase Activity. V. Serum Cholinesterase in Patients with Carcinoma. Ann. Int. Med. 52: 102 (1960).

26. Kaufman, L., Lehmann, H., \& Silk, E. Suxamethonum Apnoea in an Infant. Brit. Med. J. $i$ : 166 (1960).

27. Kalow, W., \& Staron, N. On Distribution and Inheritance of Atypical Forms of Human Serum Cholinesterase, as Indicated by Dibucaine Numbers. Canad. J. Biochem. Physiol. 35: 1305 (1957).

28. Conn, T. W.; Fajans, S. S.; Louis, L. H.; Strekten, D. H. P.; \& Johnson, R. D. Intermittent Aldosteronism in Periodic Paralysis. Lancet $i$ : 802 (1957).

29. Cohen, T. Hypokalemic Muscle Paralysis Associated with Administration of Chlorothiazide. J.A.M.A. 170: 2083 (1959).

30. Egan, T. J., \& Klein, R. Hyperkalemic Familial Periodic Paralysis. Pediatrics $24: 761$ (1959).

31. Kellerman, L., \& Posner, A. The Value of Heredity in the Detection and Study of Glaucoma. Acta XVII Council Ophth. 2: 1129 (1954).

32. Duke-Elder, S. Parson's Diseases of the Eye, p. 234. 12th ed. London: Churchill (1956).

33. Grant, W. M. Physiological and Pharmacologica! Influences upon Intraocular Pressure. Pharm. Rev. 1: 143 (1955).

34. LeE, P. F. The Influence of Epinephrine and Phenylephrine on Intraocular Pressure. A.M.A. Arch. Ophth. 60: 862 (1958).

35. Price, H. L.; Linde, H. W.; Jones, R. E.: Black. G. W.; \& Price, M. L. SympathoAdrenal Responses to General Anaesthesia in Man, and their Relationship to Haemodynamics. Anesthesiology 20: 563 (1959).

36. Kornblueth, W.; AladjemofF, L.; Magora, F.; \& Gabbay, A. Influence of General Anaesthesia on Intraocular Pressure in Man. A.M.A. Arch. Ophth. 61: 84 (1959).

37. Gartwer, S., \& Billet, E. Acute Glaucoma as a Complication of General Surgery. Am. J. Ophth. 45: 668 (1958).

38. Croll, M., \& Croll, L. J. Emotional Glaucoma. Am. J. Ophth. $49: 297$ (1960).

39. Wynands, J. E., \& Crowell, D. E. Intraocular Tension in Association with Succinylcholine and Endotracheal Intubation: A Preliminary Report. Canad. Anaesth. Soc. J. 1 : 39 (1960).

40.' Srmmons, W. D. A Review of the Data on the Occurrence of Glaucoma. Am. I. Ophth. 47: (2): 62 (1959).

41. Angenent, W. J., \& Koelle, G. B. A Possible Enzymatic Basis for the Differential Action of Mydriatics on Light and Dark Irises. J. Physiol. 119: 102 (1953).

12. Scotr, T. G. The Eye of the West African Negro: Stronger Mydriatic Drugs. Brit. J. Ophth. 29: 12 (1945).

43. Venable, H. P. Glaucoma in the Negro. J. Nat. M.A. 44: 7 (1952).

44. Chen, K. K., \& Poth, E. J. sRacial Differences as Illustrated by the Mydriatic Action of Cocaine, Euphthalmine, and Ephedrine. J. Pharmacal. \& Exper. Therap. 36: 429 (1929).

45. Sutror, P. R. N. Association between Colour of the Iris of the Eye and Reaction to Dental Pain. Nature 184: 122 (1959).

46. Editorial. Sţeely Eyes and Pain. Brit. Med. J. ii: 418 (1959).

47. Haldane, J. B. S. The Biochemistry of Genetics, p. 66. London: Allen \& Unwin (1954).

48. VEAL, T. R., \& VAN WERDEN, B. D. " Mortality of Spinal Analgesia Based on an Analysis of 30 Immediate Fatalities in a Series of 33,811 Cases. Am. J. Surg. 34: 606 (1936).

49. Trent, J. C. \& Gastner, E. Anaesthetic Death in 54,128 Consective Cases. Ann. Surg. 119: 954 (1944). 
50. Keating, V. J. Anaesthețic Problems in a Tropical Country. Proc. World Fed. Anaesthetists (1950).

51. Barlow, M. B. Cit. Keating, V. J., Anesthesia 13: 434 (1958). South Africån Med. J. (Mar. 21, 1953).

52. Phillips, L. A., \& Cohen, R. I. Operative Stress and the Adrenals. Anesthesia 14: 270 (1959).

53. KEating, V. J. Carbohydrate Metabolism: The Effects of Surgery in a Tropical Population. Anesthesia 13: 434 (1958).

54. Stirling, G. A., \& Keating, V. J. Size of the Adrenals in Jannaicans. Brit. Med. J. ii: 1016 (1958).

55. Strrling, G. A. The Adrenal Glands in Jamaican Infants. J. Path. Bact. $77: 555$ (1959).

56. Blane, G. F. Urinary 17 -Ketosteroids and Ketogenic Steroids in a Mixed Jamaican Population. Lancet $i$ : 498 (1959). 